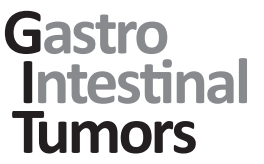

\title{
Aberrant Expression of Peroxisome Proliferator-Activated Receptors in Colorectal Cancer and Their Association with Cancer Progression and Prognosis
}

\author{
Musa Yaghoubizadeh ${ }^{a} \quad$ Leila Pishkar $^{b}$ Gholam Basatic, d \\ a Department of Biology, Science and Research Branch, Islamic Azad University, Tehran, \\ Iran; ${ }^{b}$ Department of Biology, Islamshahr Branch, Islamic Azad University, Islamshahr, \\ Iran; ' Department of Clinical Biochemistry, Faculty of Medicine, llam University of Medical \\ Sciences, Ilam, Iran; ${ }^{d}$ Clinical Microbiology Research Center, Ilam University of Medical \\ Sciences, Ilam, Iran
}

\author{
Keywords \\ Colorectal cancer $\cdot$ PPAR $\alpha \cdot$ PPAR $y \cdot$ PPAR $\delta \cdot$ Tumor tissue $\cdot$ Prognosis
}

\begin{abstract}
Introduction: Peroxisome proliferator-activated receptors (PPARs), PPAR $\alpha$, PPAR $\gamma$, and PPAR $\delta$, are nuclear ligand-activated transcription factors which presumably contribute to a broad range of pathophysiological processes, such as tumorigenesis. Nevertheless, their exact role as tumor suppressors or promoters is not straightforward in colorectal cancer (CRC). Therefore, expression values of these PPARs and their relation with tumor progression and prognosis were examined in CRC patients. Methods: In this work, the relative expression values of the PPARs were measured by real-time polymerase chain reaction in $100 \mathrm{CRC}$ tumor tissues paired with adjacent normal tissues. After that, the association between relative expression values of the PPARs in tumor tissues and the cancer progression-related clinicopathological characteristics as well as overall survival of patients were assessed. Results: While PPAR $\alpha$ and PPARS seemed to be overexpressed, PPARY was suppressed in CRC tumor tissues compared with paired adjacent normal tissues $(p=0.0001)$. The relative expressions of PPAR $\alpha$ and PPAR $\delta$ were negatively associated with tumor size, tumor grade, TNM stage, metastasis, lymphatic invasion, and decreased overall survival time $(p<0.05)$. The same associations, but in reverse direction, were found for PPAR $\gamma$. Conclusions: It was found that PPAR $\alpha$ and PPAR $\delta$ were overexpressed while PPARy was suppressed in CRC tumor tissues, and these deregulations are associated with cancer progression and poor prognosis.


Yaghoubizadeh et al:: Aberrant Expression of PPARs in Colorectal Cancer and Their

Association with Cancer Progression and Prognosis

\section{Introduction}

Colorectal cancer (CRC) was estimated to account for over 1.8 million newly diagnosed cancer cases and approximately 881,000 deaths in 2018, making it the second lethal malignancy in 185 countries [1]. Although the emergence of sophisticated diagnostic and therapeutic methods has critical effects on the treatment of CRC, the 5-year survival rate for the disease still remains low [2,3]. The presence of high inherent heterogeneity in the tumors of CRC has complicated decisions on diagnostic and treatment strategies [4]. Therefore, finding potential surrogate biomarkers involved in the tumorigenesis and progression of CRC may improve detection, prognosis, and treatment of the disease.

Peroxisome proliferator-activated receptors (PPARs), consisting of 3 distinct isoforms, PPAR $\alpha$, PPAR $\gamma$, and PPAR $\delta$, have been well known as nuclear ligand-activated transcription factors that promote the proliferation of peroxisomes and are essentially involved in many physiological processes, including glucose and lipid metabolism, inflammation, and adipogenesis [5]. PPARs have also been implicated in other biological processes, including atherosclerosis, cell differentiation, proliferation and apoptosis, and tumorigenesis [6]. There is a growing interest in the biological relevance of PPARs in gastrointestinal cancer, but their exact functions in gastrointestinal oncogenesis demand further studies [6]. In a recent study, the higher expression of PPAR $\alpha$ in pancreatic cancer patients and its association with adverse prognosis provided robust evidence for the oncogenic effect of this receptor [7]. It has been elucidated that PPAR $\alpha$, in cooperation with the enzyme HMGCS2, enhances the transcriptional activity of the oncogene Src, which consequently results in cancer cell invasion and metastasis in CRC and oral squamous cell carcinoma [8]. In addition, antagonistic repression of PPAR $\alpha$ and PPAR $\gamma$ in pancreatic and CRC cell lines demonstrated cytotoxic effects in a dose-dependent manner [9]. Nevertheless, data regarding the aberrant expression of PPAR $\gamma$ in CRC are inconsistent. While some evidence supports the cancer promoting effects of PPAR $\gamma$ in CRC $[10,11]$, more current studies suggest that it may act in an opposite direction, impeding CRC development and progression [12-15]. The involvement of PPAR $\delta$ in the tumorigenesis of many cancers, especially CRC, has been frequently attributed to its inflammatory effects [16]. Although the overexpression of PPAR $\delta$ in CRC has been reported by various studies [17-19], several other contrasting ones reported a tumor suppressing effect for it [16, 20-22].

Considering that there is no consensus on whether PPARs are up- or downregulated in $\mathrm{CRC}$, in the present study, our effort was to provide further evidence regarding their exact pathophysiology in a more clinically relevant state. Therefore, the expression of PPARs in tumor tissues of CRC patients and their association with the cancer progression and prognosis were explored.

\section{Materials and Methods}

Patients and Specimens

For the study, 100 primary tumor tissues and normal adjacent tissues (normal tissue was $>5 \mathrm{~cm}$ away from tumorous tissue) were collected from patients with CRC who had undergone curative surgical resection, between January 2014 and July 2018, at Iran National Tumor Bank (Tehran, Iran). The tissue specimens were snap frozen in liquid nitrogen quickly after surgical resection and were kept at $-80^{\circ} \mathrm{C}$ until the next preparations. Data regarding the main demographical (age at surgical resection and gender) and clinicopathological (tumor site and size, grade, TNM stage, lymph node, and vascular invasion and metastasis) characteristics of the patients were obtained from their medical documents. With regard to exclusion criteria, patients receiving other treatments (radiotherapy, chemotherapy) or having other malignancies and illnesses with confounding effects were not enrolled in the study. The patients had a survival follow-up for the first 5 years after surgical 
Yaghoubizadeh et al.: Aberrant Expression of PPARs in Colorectal Cancer and Their Association with Cancer Progression and Prognosis

Table 1. Designed primer pair set for qRT-PCR quantification in the study

\begin{tabular}{llll}
\hline Target gene & Primer sequence & Tm, ${ }^{\circ} \mathrm{C}$ & Amplicon length, bp \\
\hline PPAR $\alpha$ & F: 5'-ACTCTTGCGAGGGATCTCGG-3' & 61.39 & \multirow{2}{*}{198} \\
& R: 5'-GGAAAGGGCAAGTCCCGATG-3' & 61.03 & \\
\hline PPAR $\gamma$ & F: 5'-GGAAGGTGGGTGTGTAGTCG-3' & 60.04 & \multirow{2}{*}{168} \\
& R: 5'-GCAGAAATGCAGGCTTCTGG-3' & 59.83 & \\
\hline PPAR $\delta$ & F: 5'-AAGCAGTTGGTGAATGGCCT-3' & 60.18 & \multirow{2}{*}{157} \\
& R: 5'-GGGTAACCTGGTCGTTGAGG-3' & 60.04 & \\
\hline $32 \mathrm{M}$ & F: 5'-GGCATGGTTGTGGTTAATCTGG-3' & 59.83 & \multirow{2}{*}{194} \\
& R: 5'-AGGCCCTTTACACTGTGAGC-3' & 59.96 & \\
\hline
\end{tabular}

PPAR, peroxisome proliferator-activated receptor; $\beta 2 \mathrm{M}$, beta-2-microglobulin; $\mathrm{F}$, forward primer; $\mathrm{R}$, reverse primer; Tm, melting temperature.

procedure. A written informed consent, signed by each patient, was prerequisite for participating in the study. The study design and related protocols were confirmed by the Research Ethics Committee of Islamic Adzad University.

\section{RNA Isolation}

The total RNA of tumor and adjacent normal tissues ( 2 mg of each tissue sample) was isolated by TRIzol reagent (Invitrogen, USA) according to the manufacturer's protocol. The isolated total RNA specimens were subjected to DNase digestion (DNase Kit, Qiagen, Hilden, Germany) to eliminate any potential genomic DNA contamination. RNA quantity and purity was spectrophotometrically (absorbance ratio at 260/280 nm) analyzed on a Nanodrop 2000 system (Thermo Scientific). Furthermore, integrity of the RNAs was checked by observing the specified bands on agarose gel electrophoresis.

\section{Reverse Transcription and cDNA Synthesis}

After approving the quantity and quality of isolated RNAs, reverse transcription reactions were carried out. For the purpose, $1 \mu \mathrm{g}$ of each total RNA sample was reverse transcribed into cDNA using the PrimeScript ${ }^{\mathrm{TM}}$ 1st Strand cDNA Synthesis Kit (Takara, Otsu, Japan) according to the instructions of the manufacturer. The produced cDNA samples were preserved at $-20^{\circ} \mathrm{C}$ until the next step, quantitative real-time polymerase chain reaction (qRT-PCR) quantitation.

\section{qRT-PCR Quantification}

Quantification of the synthesized cDNAs was accomplished using RT ${ }^{2}$ SYBR Green qPCR Mastermix (Qiagen, Hilden, Germany), following the manufacturer's instructions, on an Exicycler ${ }^{\mathrm{TM}} 96$ Quantitative RealTime PCR System (Bioneer, Daejeon, Korea). The qRT-PCR reaction mixture contained $1 \mu \mathrm{L} \mathrm{cDNA} \mathrm{(5} \mathrm{ng/mL),}$ $12.5 \mu \mathrm{L} \mathrm{RT}{ }^{2}$ SYBR Green Mastermix, $2 \mu \mathrm{L}$ of related primers (150 nM), and $8.5 \mu \mathrm{L}$ RNase-free water in a final volume of $25 \mu \mathrm{L}$. All qRT-PCR reactions were run, in triplicate, with the following thermal cycling conditions: A first step at $95^{\circ} \mathrm{C}$ for $10 \mathrm{~min}$, followed by 40 cycles at $94^{\circ} \mathrm{C}$ for $15 \mathrm{~s}$, and at $60^{\circ} \mathrm{C}$ for $10 \mathrm{~min}$. A negative quality control (without cDNA) reaction was also included concurrently with the qRT-PCR quantifications. Validated primer sets, designed using Primer3 software [23] (15b), for the qRT-PCR assay are depicted in Table 1. Beta-2-microglobulin ( $\beta 2 \mathrm{M})$ was used as endogenous reference gene by which the resulting qRT-PCR data were normalized. The threshold cycle of amplification plots, at which the fluorescence signal crosses the average background noise, was automatically determined using the real-time system software. At the end of the qRT-PCR reaction, specificity of the amplified products was confirmed by melting curve analysis. Before conducting the main qRT-PCR assay, a dilution series of the cDNAs under study (PPAR $\alpha$, PPAR $\gamma$, and PPAR $\delta$ ) along with the endogenous reference cDNA $(\beta 2 \mathrm{M})$ was subjected to qRT-PCR amplification for calibration purpose. According to the plotted calibration curves, it was ascertained that amplification efficiencies of the cDNAs were very close to that of the endogenous reference $(1.01,0.98,0.99$, and 1.00 for PPAR $\alpha$, PPAR $\gamma$, PPAR $\delta$, and $\beta 2 \mathrm{M}$, respectively). The comparative normalized expression level of PPARs, in tumors relative to the adjacent normal tissues, reported as fold change, was calculated using the $2^{-\Delta \Delta C t}$ method [24]. 


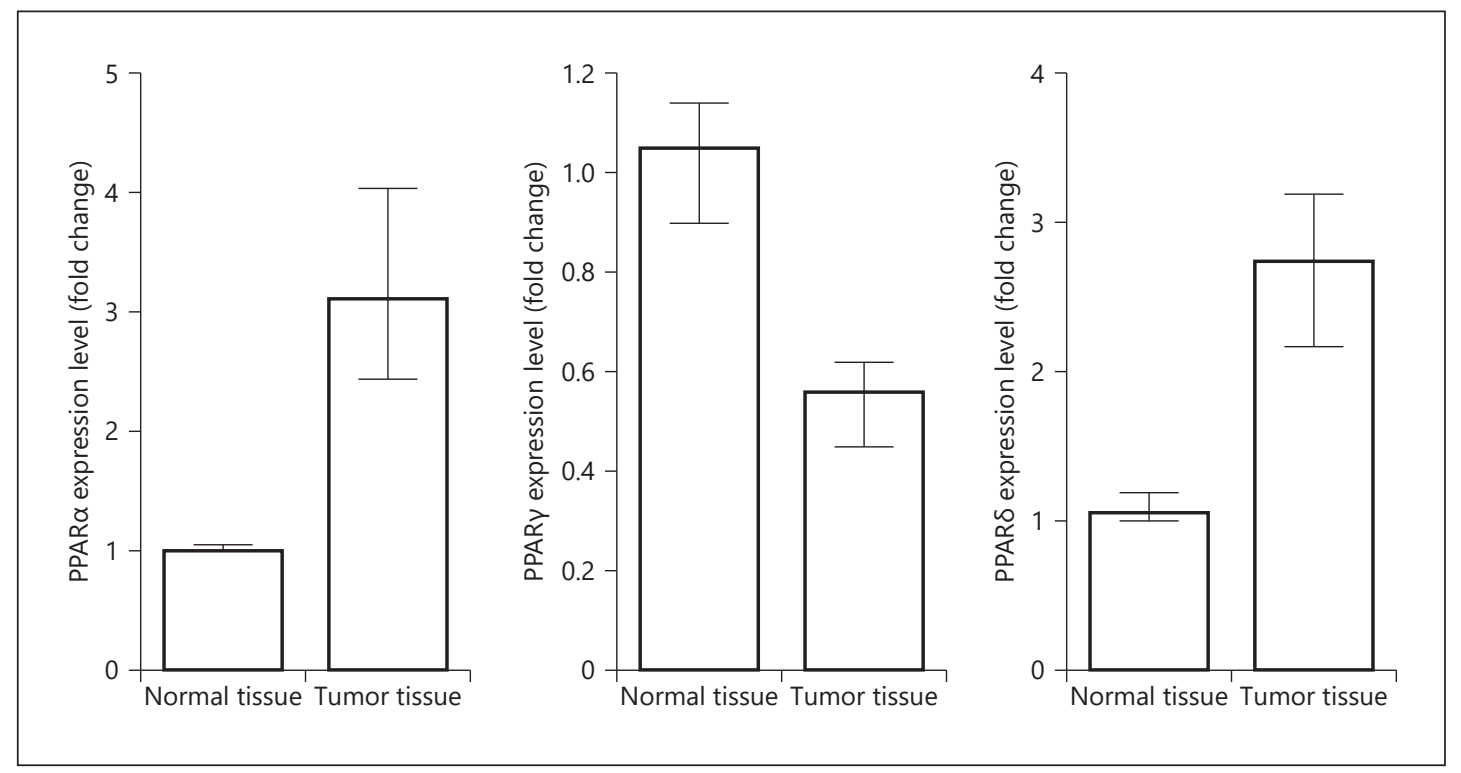

Fig. 1. Relative expression levels of PPAR $\alpha$ PPAR $\gamma$, and PPAR $\delta$ in colorectal cancer tumor tissues compared with paired adjacent normal tissues. Higher expressions of PPAR $\alpha$ and PPAR $\delta$, but lower expression of PPAR $\gamma$, were found in tumor tissues relative to adjacent normal tissues ( $p=0.0001$, Mann-Whitney U test).

Statistical Analysis

All data were statistically analyzed with SPSS software version 22.0 (SPSS Inc., Chicago, IL, USA). Comparison between the paired tumor and normal tissues for relative expression values of PPARs was performed using Wilcoxon signed-rank test. The statistically significant differences between 2 and more than 2 groups of patients were determined by Mann-Whitney U and Kruskal-Wallis tests, respectively. The overall survival effects of PPAR expression in tumor tissues were assessed using the Kaplan-Meier method and log-rank test. Univariate and multivariate Cox regression analyses were employed to determine whether the expression of PPARs in tumor tissues would be capable to serve as independent prognostic factors for CRC. The significance level for data analyses was set as a $p$ value $<0.05$.

\section{Results}

\section{Comparative Expression of PPARs in CRC Tumor Tissues and Paired Adjacent Normal}

Tissues

The relative expression amounts (expressed as fold change) of PPAR $\alpha$, PPAR $\gamma$, and PPAR $\delta$ genes in the CRC tumor tissues were compared with those in the adjacent normal tissues. As indicated in Figure 1, while the relative expression levels of PPAR $\alpha$ and PPAR $\delta$ were both significantly higher in CRC tumor tissues than in the paired normal ones ( $p=0.0001)$, the expression of PPAR $\gamma$ was remarkably decreased in the CRC tumor tissues ( $p=0.0001)$.

\section{Association between PPAR Expression Levels and the Clinicopathological Characteristics of Patients}

Relative expression values of PPAR $\alpha$, PPAR $\gamma$, and PPAR $\delta$ in the tumor tissues of CRC patients in terms of their clinicopathological information are represented in Table 2. As seen in the table, a significant increase in the expression of PPAR $\alpha$ and PPAR $\delta$ in the CRC tumor tissues was associated with advanced tumor TNM stage, grade, size, and metastasis. In contrast, a lower expression of PPAR $\gamma$ was associated with advancement of the mentioned 
Table 2. Relative expression levels of PPAR $\alpha, \operatorname{PAAR} \gamma$, and PPAR $\delta$ in colorectal cancer tumor tissues and their relationships with clinicopathologic characteristics

\begin{tabular}{|c|c|c|c|c|c|c|c|}
\hline $\begin{array}{l}\text { Clinicopathologic } \\
\text { variables }\end{array}$ & $n$ & $\begin{array}{l}\text { PPAR } \alpha \text { expression } \\
\text { level (fold change) }\end{array}$ & $\begin{array}{l}p \\
\text { value }\end{array}$ & $\begin{array}{l}\text { PPAR } \gamma \text { expression } \\
\text { level (fold change) }\end{array}$ & $\begin{array}{l}p \\
\text { value }\end{array}$ & $\begin{array}{l}\text { PPAR } \delta \text { expression } \\
\text { level (fold change) }\end{array}$ & $\begin{array}{l}p \\
\text { value }\end{array}$ \\
\hline Age & & & 0.55 & & 0.82 & & 0.80 \\
\hline$\leq 60$ years & 54 & $3.11(1.75-4.50)$ & & $0.55(0.32-0.78)$ & & $2.65(1.30-5.36)$ & \\
\hline$>60$ years & 46 & $3.09(1.99-5.02)$ & & $0.58(0.31-0.78)$ & & $2.82(1.25-4.96)$ & \\
\hline Gender & & & 0.68 & & 0.64 & & 0.74 \\
\hline Male & 60 & $3.06(1.84-5.11)$ & & $0.55(0.26-0.77)$ & & $2.80(1.46-4.97)$ & \\
\hline Female & 40 & $3.17(1.86-4.60)$ & & $0.57(0.33-0.76)$ & & $2.71(1.04-4.96)$ & \\
\hline Tumor size & & & 0.001 & & 0.016 & & 0.030 \\
\hline$\leq 5 \mathrm{~cm}$ & 54 & $2.26(1.51-3.78)$ & & $0.64(0.40-0.85)$ & & $1.96(1.14-3.74)$ & \\
\hline$>5 \mathrm{~cm}$ & 46 & $4.34(2.50-5.21)$ & & $0.46(0.27-0.62)$ & & $3.22(2.16-5.19)$ & \\
\hline TNM stage & & & 0.0001 & & 0.0001 & & 0.0001 \\
\hline 0 & 6 & $0.93(0.81-1.04)$ & & $1.00(0.93-1.02)$ & & $0.44(0.13-0.56)$ & \\
\hline I & 8 & $1.79(1.56-1.95)$ & & $0.94(0.88-0.96)$ & & $0.96(0.52-1.40)$ & \\
\hline II & 19 & $2.18(1.76-3.01)$ & & $0.78(0.69-0.84)$ & & $1.64(1.14-2.16)$ & \\
\hline III & 34 & $3.85(2.32-5.23)$ & & $0.42(0.25-0.56)$ & & $3.04(1.53-4.73)$ & \\
\hline IV & 33 & $4.36(3.20-5.31)$ & & $0.33(0.24-0.57)$ & & $5.14(3.04-7.19)$ & \\
\hline Tumor grade & & & 0.0001 & & 0.0001 & & 0.0001 \\
\hline I & 19 & $1.80(1.12-3.00)$ & & $0.89(0.53-0.99)$ & & $1.25(0.49-2.60)$ & \\
\hline II & 49 & $2.85(1.85-4.02)$ & & $0.62(0.33-0.78)$ & & $2.44(1.25-3.58)$ & \\
\hline III & 32 & $4.87(3.78-5.95)$ & & $0.37(0.26-0.56)$ & & $4.99(3.15-6.54)$ & \\
\hline Metastasis & & & 0.0001 & & 0.0001 & & 0.0001 \\
\hline M0 & 67 & $2.02(1.46-3.03)$ & & $0.72(0.56-0.88)$ & & $1.41(0.69-2.52)$ & \\
\hline M1 & 33 & $4.44(3.68-5.33)$ & & $0.33(0.24-0.54)$ & & $4.76(3.07-6.51)$ & \\
\hline Lymphatic invasion & & & 0.008 & & 0.004 & & 0.008 \\
\hline Negative & 44 & 2.23 (1.78-4.09) & & $0.67(0.44-0.84)$ & & $2.13(1.19-3.35)$ & \\
\hline Positive & 56 & $4.06(2.26-5.18)$ & & $0.45(0.24-0.64)$ & & $3.23(1.67-5.77)$ & \\
\hline Vascular invasion & & & 0.11 & & 0.17 & & 0.08 \\
\hline Negative & 58 & $2.49(1.79-4.50)$ & & $0.59(0.34-0.81)$ & & $2.31(1.23-4.28)$ & \\
\hline Positive & 42 & $3.69(2.33-5.06)$ & & $0.51(0.26-0.63)$ & & $3.29(1.80-5.35)$ & \\
\hline
\end{tabular}

Data are expressed as median (25th-75th interquartile range) and number.

clinicopathological factors. As delineated in Table 2, the increase in PPAR $\alpha$ and PPAR $\delta$ or decrease in PPAR $\gamma$ expression is accompanied by the progression and expansion of CRC tumors.

Association between PPAR Expression Levels and the Overall Survival Rate of Patients

To assign prognosis evaluations, the total of 100 CRC patients who were suitable for the retrospective cohort study were scheduled for a 5-year follow-up period until death or censoring. In this regard, at first, the median expression values (after log-transformation) of PPAR $\alpha$, PPAR $\gamma$, and PPAR $\delta$ in CRC tumor tissues were calculated, according to which the patients were classified into high- and low-expression subsets. Then, Kaplan-Meier survival curve analysis and log-rank test were utilized to determine the effect of PPAR expression of tumor tissue on the overall survival span of CRC patients (Fig. 2). From the analyses, it emerged that patients with higher expressions of PPAR $\alpha$ and PPAR $\delta$ in tumor tissues deceased sooner than those patients whose tumors had lower expression levels for the 2 genes. The opposite pattern was true for the expression of PPAR $\gamma$. That is, higher levels of PPAR $\gamma$ were associated with a shorter overall survival rate of CRC patients (Fig. 2). Additionally, to 


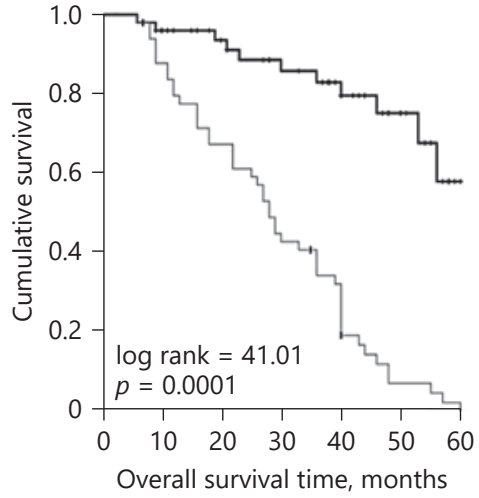

$\Omega$ Low PPAR $\alpha$ expression $(<3.11, n=50)$

$\rightarrow$ High PPAR $\alpha$ expression (>3.11, $n=50$ )

+ Low PPAR $\alpha$ expression-censored

I High PPAR $\alpha$ expression-censored

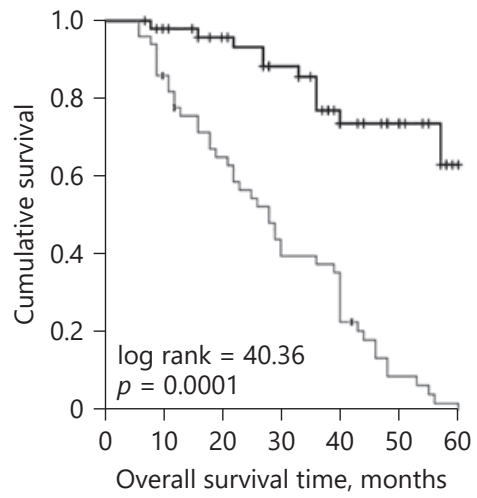

Low PPAR $\delta$ expression $(<2.73, n=50)$

High PPAR $\delta$ expression $(>2.73, n=50)$

+ Low PPARS expression-censored

I High PPARS expression-censored

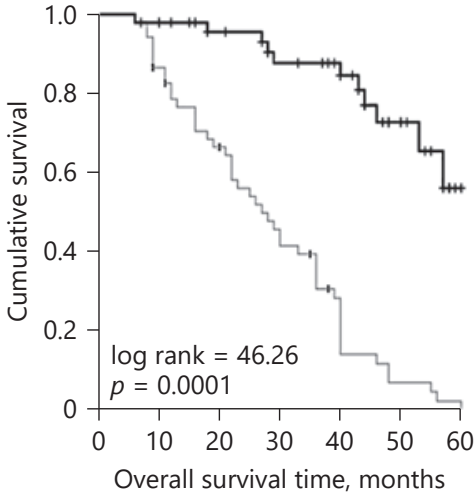

$\rightarrow$ Low PPARy expression $(<0.56, n=52)$

$\rightarrow$ High PPARy expression ( $>0.56, n=48$ )

+ Low PPARy expression-censored

I High PPARy expression-censored

Fig. 2. Kaplan-Meier survival curve analyses based on the median expression levels of PPAR $\alpha, P P A R \delta$, and PPAR $\gamma$ in tumor tissues of patients with colorectal cancer. Higher expressions of PPAR $\alpha$ and PPAR $\delta$, but lower expression of PPAR $\gamma$, were associated with decreased overall survival of patients.

ascertain the adjusted prognostic effects of PPAR expression, univariate and multivariate Cox regression analyses were arranged. Of all clinicopathological factors entered in the Cox regression evaluations, the altered expression of PPARs, TNM stage, grade, and metastasis status of tumors were certified as reliable independent predictors of the overall survival rate in CRC patients (Table 3).

\section{Discussion/Conclusion}

The current literature has reportedly emphasized the definite involvement of PPAR expression in tumorigenesis, even though the exact functions of PPARs as tumor promoters or suppressors are not clear-cut and deserve to be resolved $[25,26]$. In this regard, we noticed, in the present study, that PPAR expressions are explicitly deregulated in CRC, with PPAR $\alpha$ and PPAR $\delta$ being upregulated, while PPAR $\gamma$ is downregulated. More importantly, the aberrant expression levels of PPARs in tumor tissues were apparently associated with progression and poor prognosis of CRC. Here, our findings offer another evidence for better judgement regarding the controversies on the different roles of PPARs in CRC.

As initially mentioned, the ability of PPAR $\alpha$ to promote progression of CRC and oral squamous cell carcinoma [8] is in line with the findings we gained in the current study. Similarly, the higher expression of PPAR $\alpha$ in pancreatic cancer tissues and its consequent worse prognostic effects [7] may be interpreted in this sense. Despite these data, some earlier studies have drawn doubt on the carcinogenetic effects of PPAR $\alpha[25,27,28]$. The essence of those studies is based on various PPAR $\alpha$ agonists which exhibited inhibitory effects on angiogenesis and inflammation in animal models $[27,28]$. Given that the mechanistic rationale underlying these anti-carcinogenesis effects may be somewhat inconsistent in humans, because of the significant differences in PPAR $\alpha$ expression between rodents and humans, as well as ineffectiveness of agonists in humans [29], caution should be exerted in extrapolating 


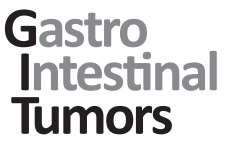

\begin{tabular}{l|l}
\hline Gastrointest Tumors 2020;7:11-20 \\
\hline DOI: 10.1159/000503995 & $\begin{array}{l}\text { @ 2019 The Author(s). Published by S. Karger AG, Basel } \\
\text { www.karger.com/gat }\end{array}$
\end{tabular}

Yaghoubizadeh et al.: Aberrant Expression of PPARs in Colorectal Cancer and Their Association with Cancer Progression and Prognosis

Table 3. Univariate and multivariate Cox regression analyses to find independent predictors of overall survival rate in patients with colorectal cancer

\begin{tabular}{|c|c|c|c|c|}
\hline \multirow[t]{2}{*}{ Clinicopathological factors } & \multicolumn{2}{|l|}{ Univariate } & \multicolumn{2}{|l|}{ Multivariate } \\
\hline & $\operatorname{HR}(95 \% \mathrm{CI})$ & $p$ value & $\operatorname{HR}(95 \% \mathrm{CI})$ & $p$ value \\
\hline Age $(\leq 60$ years $/>60$ years $)$ & $0.84(0.50-1.42)$ & 0.515 & $0.66(0.56-1.97)$ & 0.88 \\
\hline Gender (male/female) & $1.32(0.77-2.73)$ & 0.30 & $1.18(0.64-2.18)$ & 0.58 \\
\hline Tumor size $(>5 \mathrm{~cm}$ vs. $\leq 5 \mathrm{~cm})$ & $2.15(1.25-3.70)$ & 0.005 & $1.06(0.59-1.89)$ & 0.84 \\
\hline TNM stage (III+IV/0+I+II) & $55.57(6.42-481.29)$ & 0.0001 & $2.55(1.63-4.00)$ & 0.001 \\
\hline Tumor grade (III/I+II) & $3.11(1.85-5.25)$ & 0.0001 & $1.40(0.89-2.19)$ & 0.14 \\
\hline Distant metastasis (M1/M0) & $8.03(4.02-16.03)$ & 0.0001 & $2.31(0.96-5.54)$ & 0.06 \\
\hline Lymphatic invasion (positive/negative) & $2.37(1.32-4.25)$ & 0.004 & $1.72(0.69-4.28)$ & 0.24 \\
\hline Vascular invasion (positive/negative) & $1.98(1.16-3.39)$ & 0.013 & $1.64(0.31-3.39)$ & 0.26 \\
\hline PPAR $\alpha$ expression level (high/low) & $6.52(3.35-12.68)$ & 0.0001 & $2.39(1.09-5.20)$ & 0.03 \\
\hline PPAR $\gamma$ expression level (high/low) & $0.14(0.07-0.27)$ & 0.0001 & $0.37(0.17-0.83)$ & 0.02 \\
\hline PPAR $\delta$ expression level (high low) & $6.41(3.29-12.45)$ & 0.0001 & $2.37(1.09-5.14)$ & 0.03 \\
\hline
\end{tabular}

TNM, tumor node metastasis; CI, confidence interval; HR, hazard ratio.

these findings to humans. Furthermore, opposed to the latter reports, there is an antagonistic repression of PPAR $\alpha$ in pancreatic and CRC cell lines that showed to be lethal for the cells [9]. Altogether, this set of data supports the tumor promoting function of PPAR $\alpha$ in humans, as we found its upregulation in CRC in the present study.

As with the scenario of PPAR $\alpha$, there are some paradoxical data regarding the role of PPAR $\delta$ in CRC tumorigenesis [16]. While the overexpression of PPAR $\delta$ in relation with tumor progression has been indicated in CRC by a number of studies [17-19], some former experiments showed an inverse association between PPAR $\delta$ and CRC [16, 20-22]. These inconsistencies may predominately come from preclinical studies with mouse models [16] in which the behavior of PPAR $\delta$ in noncancerous cells was reported to be significantly different from that in cancer cells [30]. Apart from the debated data, in the most recent comprehensive study, Zuo et al. [19] emphasized that PPAR $\delta$ is upregulated in human CRC and found a significant association between high PPAR $\delta$ in primary tumors with stage III and shortened metastasis-free survival. More notably, a robust mechanistic explanation was reported in which the upregulation of PPAR $\delta$ induced by a high-fat diet in intestinal stem and progenitor cells could lead to their transformation into malignant cells with the capability to form adenoma tumors [31]. Further, in this regard, it has been shown that the activation of PPAR $\delta$ functions as a contributor to CRC metastasis through promoting the proliferation of colonic cancer stem cells [32].

Similarly, the same kind of result, more or less, was attained in the current study. Thus, our findings add more evidence on the tumor driving function of PPAR $\delta$ in CRC and its clinical relevance. Nevertheless, the latest information could not rule out the necessity for further corroborating investigations.

In this study, a reciprocal relationship was noted between decreased PPAR $\gamma$ expression level and progression of CRC, accompanied with a decline in the overall survival rate of patients. Consistent with the results achieved here, Pancione et al. [33] observed that reduced expression of PPAR $\gamma$ in CRC tissues due to epigenetic silencing is accompanied with a detrimental impact, including CRC progression and patients' worse prognosis. Further, in this regard, it has been pointed out that PPAR $\gamma$, through modulating a network of proteins involved in cell differentiation, death, growth, and survival, functions as a suppressor of CRC tumorigenesis [34]. Also, Beyaz et al. [35] found mechanistic evidence that the suppression of PPAR $\gamma$ 
Yaghoubizadeh et al.: Aberrant Expression of PPARs in Colorectal Cancer and Their Association with Cancer Progression and Prognosis

coactivator $1 \alpha$ (prerequisite for PPAR $\gamma$ effectiveness) by tumor microenvironment signals compromised the immunosurveillance and antitumor function of $\mathrm{T}$ cells through impairing their mitochondrial biogenesis and oxidative metabolism, consequently resulting in tumor progression. Interestingly, according to a very recent clinical study, the inverse association of certain CRC-associated microRNAs, namely, 27b, 130b, and 138, with promoter hypermethylation and decreased expression of PPAR $\gamma$ in patients with CRC has undoubtedly authenticated its tumor protective effect [36]. On the other hand, opposite to our and the latter studies, some other researches showed that PPAR $\gamma$ is not significantly altered in CRC and may not serve as an indicator of CRC progression and prognosis $[37,38]$. Although the majority of the existing reports support a tumor suppressive function for PPAR $\gamma$, there is still some uncertainty on its role in CRC pathogenesis, prompting further evaluations.

In this study, the sample size might be found relatively small, which possibly could reduce the power of correlational and survival analyses. Further studies with a larger cohort of such patients may enhance the reliability of the results. In addition, given the observational nature of the study, a cause and effect link could not be inferred from the association between the PPARs and clinicopathological features. Despite the limitations, we point out the involvement of PPARs in CRC expansion and patients' survival.

\section{Conclusion}

The results of this work demonstrated that the expression of the 3 PPAR genes, PPAR $\alpha$, PPAR $\gamma$, and PPAR $\delta$, is significantly altered in CRC tumor tissues relative to paired adjacent normal tissues, with PPAR $\alpha$ and PPAR $\delta$ being overexpressed and PPAR $\gamma$ being suppressed. Additionally, expression levels of these genes were correlated with CRC progression-related clinicopathological features and prognosis of CRC patients.

\section{Acknowledgement}

We would like to express our best appreciation to the staff of Iran National Tumor Bank of Cancer Institute in Imam Khomeini Hospital for providing the human specimens and technical assistance.

\section{Statement of Ethics}

A written informed consent, signed by each patient, was prerequisite for participating in the study. The study design and related protocols were confirmed by the Research Ethics Committee of Islamic Adzad University.

\section{Disclosure Statement}

The authors have no conflicts of interest to declare.

\section{Funding Sources}

The financial support for the study was provided by the Islamic Azad University (grant number 132655). 
Yaghoubizadeh et al.: Aberrant Expression of PPARs in Colorectal Cancer and Their Association with Cancer Progression and Prognosis

\section{Author Contributions}

Gholam Basati designed the study, conducted experiments, evaluated data, and wrote the manuscript. Musa Yaghoubizadeh performed experiments, analyzed data, and revised the manuscript. Leila Pishkar contributed in performing experiments, data acquisition, and interpretation and revising the manuscript. All authors verified the final manuscript.

\section{References}

1 Bray F, Ferlay J, Soerjomataram I, Siegel RL, Torre LA, Jemal A. Global cancer statistics 2018: GLOBOCAN estimates of incidence and mortality worldwide for 36 cancers in 185 countries. CA Cancer J Clin. 2018 Nov; 68(6): 394-424.

2 Tang V, Boscardin WJ, Stijacic-Cenzer I, Lee SJ. Time to benefit for colorectal cancer screening: survival metaanalysis of flexible sigmoidoscopy trials. BMJ. 2015 Apr;350:h1662.

3 Bouvier AM, Launoy G, Bouvier V, Rollot F, Manfredi S, Faivre J, et al. Incidence and patterns of late recurrences in colon cancer patients. Int J Cancer. 2015 Nov;137(9):2133-8.

4 Blank A, Roberts DE 2nd, Dawson H, Zlobec I, Lugli A. Tumor Heterogeneity in Primary Colorectal Cancer and Corresponding Metastases. Does the Apple Fall Far from the Tree? Front Med (Lausanne). 2018 Aug;5:234.

5 Chinetti G, Fruchart JC, Staels B. Peroxisome proliferator-activated receptors (PPARs): nuclear receptors at the crossroads between lipid metabolism and inflammation. Inflamm Res. 2000 Oct;49(10):497-505.

6 Pazienza V, Vinciguerra M, Mazzoccoli G. PPARs signaling and cancer in the gastrointestinal system. PPAR Res. 2012;2012:560846.

7 Xue J, Zhu W, Song J, Jiao Y, Luo J, Yu C, et al. Activation of PPAR $\alpha$ by clofibrate sensitizes pancreatic cancer cells to radiation through the Wnt/ $\beta$-catenin pathway. Oncogene. 2018 Feb;37(7):953-62.

8 Chen SW, Chou CT, Chang CC, Li YJ, Chen ST, Lin IC, et al. HMGCS2 enhances invasion and metastasis via direct interaction with PPAR $\alpha$ to activate Src signaling in colorectal cancer and oral cancer. Oncotarget. 2017 Apr; 8(14):22460-76.

9 Ammazzalorso A, De Lellis L, Florio R, Bruno I, De Filippis B, Fantacuzzi M, et al. Cytotoxic effect of a family of peroxisome proliferator-activated receptor antagonists in colorectal and pancreatic cancer cell lines. Chem Biol Drug Des. 2017 Nov; 90(5):1029-35.

10 Chen LC, Hao CY, Chiu YS, Wong P, Melnick JS, Brotman M, et al. Alteration of gene expression in normalappearing colon mucosa of APC(min) mice and human cancer patients. Cancer Res. 2004 May;64(10):3694700.

11 Yang K, Fan KH, Lamprecht SA, Edelmann W, Kopelovich L, Kucherlapati R, et al. Peroxisome proliferatoractivated receptor $\gamma$ agonist troglitazone induces colon tumors in normal C57BL/6J mice and enhances colonic carcinogenesis in Apc1638 N/+ Mlh1+/- double mutant mice. Int J Cancer. 2005 Sep;116(4):495-9.

12 Sabatino L, Fucci A, Pancione M, Colantuoni V. PPARG epigenetic deregulation and its role in colorectal tumorigenesis. PPAR Res. 2012;2012:687492.

13 Aires V, Brassart B, Carlier A, Scagliarini A, Mandard S, Limagne E, et al. A role for peroxisome proliferatoractivated receptor gamma in resveratrol-induced colon cancer cell apoptosis. Mol Nutr Food Res. 2014 Sep; 58(9):1785-94.

14 Assumpção JA, Magalhães KG, Corrêa JR. Correction to: the role of ppary and autophagy in ros production, lipid droplets biogenesis and its involvement with colorectal cancer cells modulation. Cancer Cell Int. 2017 Nov; 17(1): 99.

15 Hashimoto K, Ethridge RT, Evers BM. Peroxisome proliferator-activated receptor gamma ligand inhibits cell growth and invasion of human pancreatic cancer cells. Int J Gastrointest Cancer. 2002;32(1):7-22.

16 Liu Y, Colby JK, Zuo X, Jaoude J, Wei D, Shureiqi I. The Role of PPAR- $\delta$ in Metabolism, Inflammation, and Cancer: Many Characters of a Critical Transcription Factor. Int J Mol Sci. 2018 Oct;19(11):E3339.

17 Takayama O, Yamamoto H, Damdinsuren B, Sugita Y, Ngan CY, Xu X, et al. Expression of PPARdelta in multistage carcinogenesis of the colorectum: implications of malignant cancer morphology. Br J Cancer. 2006 Oct; 95(7):889-95.

18 Yoshinaga M, Taki K, Somada S, Sakiyama Y, Kubo N, Kaku T, et al. The expression of both peroxisome proliferator-activated receptor delta and cyclooxygenase-2 in tissues is associated with poor prognosis in colorectal cancer patients. Dig Dis Sci. 2011 Apr;56(4):1194-200.

19 Zuo X, Xu W, Xu M, Tian R, Moussalli MJ, Mao F, et al. Metastasis regulation by PPARD expression in cancer cells. JCI Insight. 2017 Jan;2(1):e91419.

20 You M, Yuan S, Shi J, Hou Y. PPAR $\delta$ signaling regulates colorectal cancer. Curr Pharm Des. 2015;21(21):2956-9.

$21 \mathrm{Xu}$ M, Zuo X, Shureiqi I. Targeting peroxisome proliferator-activated receptor- $\beta / \delta$ in colon cancer: how to aim? Biochem Pharmacol. 2013 Mar;85(5):607-11.

22 Peters JM, Gonzalez FJ, Müller R. Establishing the Role of PPAR $\beta / \delta$ in Carcinogenesis. Trends Endocrinol Metab. 2015 Nov;26(11):595-607.

23 Untergasser A, Cutcutache I, Koressaar T, Ye J, Faircloth BC, Remm M, et al. Primer3-new capabilities and interfaces. Nucleic Acids Res. 2012 Aug;40(15):e115. 
24 Livak KJ, Schmittgen TD. Analysis of relative gene expression data using real-time quantitative PCR and the 2(-Delta Delta C(T)) Method. Methods. 2001 Dec;25(4):402-8.

25 Peters JM, Shah YM, Gonzalez FJ. The role of peroxisome proliferator-activated receptors in carcinogenesis and chemoprevention. Nat Rev Cancer. 2012 Feb;12(3):181-95.

26 Gou Q, Gong X, Jin J, Shi J, Hou Y. Peroxisome proliferator-activated receptors (PPARs) are potential drug targets for cancer therapy. Oncotarget. 2017 Jul;8(36):60704-9.

27 Pozzi A, Ibanez MR, Gatica AE, Yang S, Wei S, Mei S, et al. Peroxisomal proliferator-activated receptor-alphadependent inhibition of endothelial cell proliferation and tumorigenesis. J Biol Chem. 2007 Jun;282(24): 17685-95.

28 Panigrahy D, Kaipainen A, Huang S, Butterfield CE, Barnés CM, Fannon M, et al. PPARalpha agonist fenofibrate suppresses tumor growth through direct and indirect angiogenesis inhibition. Proc Natl Acad Sci USA. 2008 Jan;105(3):985-90.

29 Brown JD, Plutzky J. Peroxisome proliferator-activated receptors as transcriptional nodal points and therapeutic targets. Circulation. 2007 Jan;115(4):518-33.

30 Müller-Brüsselbach S, Kömhoff M, Rieck M, Meissner W, Kaddatz K, Adamkiewicz J, et al. Deregulation of tumor angiogenesis and blockade of tumor growth in PPARbeta-deficient mice. EMBO J. 2007 Aug;26(15):3686-98.

31 Scharping NE, Menk AV, Moreci RS, Whetstone RD, Dadey RE, Watkins SC, et al. The Tumor Microenvironment Represses T Cell Mitochondrial Biogenesis to Drive Intratumoral T Cell Metabolic Insufficiency and Dysfunction. Immunity. 2016 Aug;45(2):374-88.

32 Wang D, Fu L, Wei J, Xiong Y, DuBois RN. PPAR $\delta$ Mediates the Effect of Dietary Fat in Promoting Colorectal Cancer Metastasis. Cancer Res. 2019 Sep;79(17):4480-90.

33 Pancione M, Sabatino L, Fucci A, Carafa V, Nebbioso A, Forte N, et al. Epigenetic silencing of peroxisome proliferator-activated receptor $\gamma$ is a biomarker for colorectal cancer progression and adverse patients' outcome. PLoS One. 2010 Dec;5(12):e14229.

34 Milone MR, Pucci B, Colangelo T, Lombardi R, Iannelli F, Colantuoni V, et al. Proteomic characterization of peroxisome proliferator-activated receptor- $\gamma$ (PPAR $\gamma)$ overexpressing or silenced colorectal cancer cells unveils a novel protein network associated with an aggressive phenotype. Mol Oncol. 2016 Oct;10(8):134462.

35 Beyaz S, Mana MD, Roper J, Kedrin D, Saadatpour A, Hong SJ, et al. High-fat diet enhances stemness and tumorigenicity of intestinal progenitors. Nature. 2016 Mar;531(7592):53-8.

36 Motawi TK, Shaker OG, Ismail MF, Sayed NH. Peroxisome Proliferator-Activated Receptor Gamma in Obesity and Colorectal Cancer: the Role of Epigenetics. Sci Rep. 2017 Sep;7(1):10714.

37 Yun SH, Roh MS, Jeong JS, Park JI. Peroxisome proliferator-activated receptor $\gamma$ coactivator-1 $\alpha$ is a predictor of lymph node metastasis and poor prognosis in human colorectal cancer. Ann Diagn Pathol. 2018 Apr;33. 11-6.

38 Zafari V, Hashemzadeh S, Hosseinpour Feizi M, Pouladi N, Rostami Zadeh L, Sakhinia E. mRNA expression of nuclear factor of activated T-cells, cytoplasmic 2 (NFATc2) and peroxisome proliferator-activated receptor gamma (PPARG) transcription factors in colorectal carcinoma. Bosn J Basic Med Sci. 2017 Aug;17(3):255-61. 